\title{
ASSESMENT OF EMOTIONAL FUNCTIONING AND SELF-PERCEPTION IN POST MASTECTOMY WOMEN
}

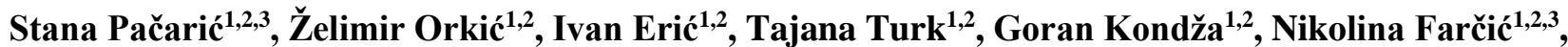 \\ Marta Biljan $^{1,2}$, Zvjezdana Gvozdanović ${ }^{1,3,4}$, Andrea Milostić-Srb ${ }^{3}$, Ivana Barać ${ }^{3}$ \& Ana Nemčić ${ }^{2}$ \\ ${ }^{1}$ Faculty of Medicine, University Josip Juraj Strossmayer, Osijek, Croatia \\ ${ }^{2}$ University Hospital Centre Osijek, Osijek, Croatia \\ ${ }^{3}$ Faculty of Dental Medicine and Health Osijek, University Josip Juraj Strossmayer, Osijek, Croatia \\ ${ }^{4}$ General County Hospital Našice, Našice, Croatia
}

received: 23.10.2019;

revised: 17.9.2020;

accepted: 15.5.2021

\section{SUMMARY}

Background: Breast cancer is the most common cancer in women which affects them emotionally and psychologically. The aim of this research was to examine emotional functioning and self-perception in post mastectomy women.

Subjects and methods: This cross-sectional single-center study included 101 women with breast cancer one month and one year after mastectomy. It was conducted using anonymous questionnaires developed by the European Organization for Research and Treatment of Cancer (EORTC): EORTC Quality of Life questionnaire (QLO) - C 30 (version 3), questionnaire with breast cancer module EORTC QLQ BR-23 and a sociodemographic questionnaire.

Results: Compared to results one month after mastectomy, in women one year after mastectomy there was significantly less tension (Mann-Whitney $U$ test, $p=0.011$ ) and emotional irritability (Mann- Whitney $U$ test, $p=0.013$ ), also the memory problems declined (Mann-Whitney $U$ test, $p=0.008)$. Discomfort with hair loss affected all parameters except concentration problems. The participants felt less physical attractive $(p=0.647)$, were worried $(p=0.645)$ and less feminine due to illness $(p=0.638)$. A year after surgery there was no connection between anxiety and observed parameters.

Conclusion: Breast cancer affects emotional functioning and self-perception of women especially in early postoperative period and during cancer treatment. A year after surgery there was no more connection between anxiety and hair loss discomfort. Patients need medical, social and psychological support during and after breast cancer treatment.

Key words: breast cancer - mastectomy - emotional functioning - image - woman

$$
* * * * * *
$$

\section{INTRODUCTION}

Breast cancer is the most common cancer in females which affects them emotionally and psychologically (Harris et al. 2000). In the Republic of Croatia, breast cancer is a significant public health problem, being the second cause of death after cardiovascular diseases. For the period between 2010 and 2014, the age-standardized incidence rate in the year 2014 was 119.2 cases per 100.000 women, with a mortality rate of $48.3 \%$. There are 2644 (26\%) new cases every year (HZJZ 2018). Breast cancer treatment in the early stage may include surgery, radiotherapy and systemic therapies, such as chemotherapy, hormonal therapy or targeted drugs. These treatment modalities significantly increased positive treatment outcome and survival rates (Cardoso et al. 2019). Being diagnosed and treated with breast cancer can have negative influence on physical and emotional wellbeing of women due to undesirable effects of treatment, fear of death and a fear of social isolation (You \& Lu 2014). Furthermore, breast cancer treatment can lead to functional impairment, breast sensory loss, changes in self-image perception, as well as anxiety, depression and other emotional and psychological difficulties (Lara et al. 2012).
Breast cancer patients are also affected physically. They experience personal discontent as a consequence of deformed body after mastectomy and have problems accepting their new body image thus developing a negative self-image (Keskin \& Gumus 2011). Body image reflects a complex construct that involves perceptions, thoughts, feelings, and behaviors related to the entire body and its functioning (Fingeret et al. 2014). Body image can be affected by various changes in physical, psychological and social functioning which occur in relation to breast cancer treatment (de Morais et al. 2016) such as postoperative wounds and scars, sensory deficits, arm and shoulder functional impairment (Recio-Saucedo et al. 2016, Teo et al. 2016); hair loss and weight gain due to chemotherapy (Zavos \& Valachis 2016, Choi et al. 2014); damaged skin, dermatitis and pain following radiotherapy (Speers $\&$ Pierce 2016); as well as premature menopause, discomfort and vasomotoric symptoms following hormonal therapy (Rossi et al. 2016).

Breast loss is related to woman's identity, her sexuality and self-perception. Therefore, there is no surprise that almost one third of breast cancer survivors, especially young women, experience stress which is directly linked to distorted body image (Przezdziecki et al. 2012). Hair is perceived of one of 
the most delicate aspects of human appearance. Alopecia or hair loss is a disturbing symptom with a major effect on quality of life. Hair loss is often followed by grief and loss of self-esteem (Mirmirani 2013). Hair loss is most common during first 6 weeks of chemo or hormonal therapy. Within 3 months after completion of therapy hair growth rate returns to normal, pretreatment values (Kanti et al. 2014). Many women who have lost their hair due to chemotherapy will find a way to hide their loss wearing various head covers or wigs (Coe et al. 2013). Previous studies on breast cancer patients showed that the quality of life improves during 6 months after operation, but the anxiety remains constant even a year following operation and treatment (Härtl et al. 2010). Apart from difficulties in emotional functioning, breast cancer survivors experience neuropsychological impairment that can lead to motoric deficits (Fallowfield \& Jenkins 2015). Previous study has shown that among women who had received chemotherapy within a year following surgery, one third of them had experienced cognitive decline on the beginning of the treatment (Shilling et al. 2005). It is of utmost importance to provide psychosocial care during re-entry phase (ie. several months immediately after completion of primary medical treatments). It is expected that psychosocial concerns will increase during re-entry period since some patients perceive loss of stability provided by routine medical treatments and accompanying support, as well as fear of new professional and social challenges (Stanton 2012).

Breast cancer significantly influences body image, (Keskin \& Gumus 2011) and therefore can have a negative impact on overall quality of life (Husić \& Brkljačić Žagrović 2010, Šeparović et al. 2019). Peterson et al in-literature review (Peterson et al 2016) found that younger women were experiencing body image disturbance years after treatment as well as other distressing symptoms. Agnieszka J. Słowik found a positive correlation of the emotional functioning variable with the assessment of future perspectives and body image (Słowik et al. 2017). In Croatia, research studies were conducted regarding quality of life of women that have breast cancer (Murgić et al. 2012, Dujmović et al. 2017), however, no research has been done to evaluate the effect of emotional functioning on body image of women after mastectomy. Psychological rehabilitation from consequences of breast cancer and side effects of their treatment is a major challenge for modern psychooncology (Gregurek et al. 2010, de la Torre-Luque et al. 2016). Although advances have been made in understanding effects of treatment on quality of life of breast cancer patients, some unsolved questions remain. The aim of this study was to examine emotional functioning and self-perception in breast cancer patients, one month and one year after mastectomy.

\section{SUBJECTS AND METHODS}

This cross-sectional study of quality of life of breast cancer patients was conducted on two groups of patients - after a month and after a year from mastectomy. Only female patients were involved because breast cancer is the most common cancer in women with gender-specific problems that arise during treatment, whereas it is extremely rare in male population with incidence rate ratios for male breast cancer in relation to female breast cancer incidence per 100000 woman-years is $1-2,1$ (Kreiter et al. 2014).

The study was conducted at the University Hospital Osijek, during the period from July 2015 to June 2016. The research was approved by the Hospital Ethics Committee (reference number 25-1: 11425-3/2015). The questionnaires used in the research were developed by the European Organization for Research and Treatment of Cancer (EORTC) and approved and translated into Croatian by EORTC Quality of Life Group. Only women who had had a mastectomy with a positive pathohistological finding were included in the study. There were no restrictions regarding specific pathohistological finding in cancer type. Patients under 18 years or over 75 years, those with a life expectancy less than a year, with cognitive and/or mental diseases, illiterate, and those were unable to communicate in the Croatian language were excluded from the study. In total, 108 patients met the inclusion criteria. However, 5 patients withdrew the consent, and 2 questionnaires were not correctly completed, decreasing the number of participants to $101(93.5 \%)$. In order to notice the effect of 0.6 difference in numerical variables between the two independent participant groups, with 0.05 difference in significance and power of 0.8 , the minimum size needed for statistical sample was 45 participants per group, ie. total sample size of 90 participants (this calculation was made using $G$ *Power software version 3.1.2, developed by Franz Faul, University of Kiel, Germany). The participants were enrolled during follow up in a thoracic surgery clinic. One group of patients had a mastectomy a month ago and were at that time undergoing adjuvant therapy. The other group had a mastectomy a year ago and had completed cancer treatment. Before being asked to participate voluntarily, all participants were informed of the study's objectives and anonymity. Upon giving informed consent, the participants were also informed of the confidentiality of personal data and given the anonymous questionnaire which they completed and handed to the researcher. Filling out the questionnaire lasted for 20 minutes.

\section{Materials}

The EORTC QLQ-C 30 (version 3) is composed of 30 single items, ie. five functional subscales: physical, role, cognitive, emotional, and social functioning. In this research the functional scales were used: 
- EF emotional scale (Q21 Did you feel tense? Q22 Did you worry? Q23 Did you feel irritable? and Q24 Did you feel depressed?)

- $C F$ cognitive scale (Q20 Have you had difficulty in concentrating on things, like reading a newspaper or watching television? Q25 Have you had difficulty remembering things?).

The EORTC QLQ- BR 23, with a module specific to tumor site, is composed of four functional subscales: body image, sexual functioning, sexuality, and future perspective. We have used functional scales:

- BRBI body image (Q39 Have you felt physically less attractive as a result of your disease or treatment? Q40 Have you been feeling less feminine as a result of your disease or treatment?, Q41 Did you find it difficult to look at yourself naked?, and Q42 Have you been dissatisfied with your body?).

- Symptom scales/items Q34. Have you lost any hair?

In this study, Cronbach Alpha for the emotional domain was 0.889 , for the cognitive domain 0.675 and for the self-image 0.951 .

A 4-point Likert scale was used for scoring: 1 (not at all), 2 (rarely), 3 (often), and 4 (almost always). A higher score on the functional scale correlates to higher levels of functional level, while a higher score on the symptom scale correlates to higher (worse) levels of symptoms (Fayers et al. 2001).

\section{Statistical methods}

Category results were presented in absolute and relative frequencies. Numerical data was described using arithmetic mean and standard deviation, or median and interquartile range, depending on normal distribution. Differences in categorical variables were analyzed with chi square, and, if necessary, with Fisher's exact test. The Shapiro-Wilk test was used to analyze normality of distribution for numerical variables. Differences in numerical variables were analyzed with Student's t-test. The Mann-Whitney $U$ test was used for variables deviating from normal distribution. Spearman's rank correlation coefficient was used to assess dependence between two variables (Rho). All $\mathrm{p}$ values were two sided. Significance level was set at Alpha $=0.05$. The MedCalc Statistical Software version 18.2.1 was used for statistical analysis (MedCalc Software bvba, Ostend, Belgium; http://www.medcalc.org; 2018).

Table 1. The mean age of the patients and age upon the illness by groups

\begin{tabular}{|c|c|c|c|c|}
\hline & \multicolumn{3}{|c|}{ Arithmetric mean (standard deviation) } & \multirow{2}{*}{$\mathrm{p}^{*}$} \\
\hline & One month after the surgery & One year after the surgery & Total & \\
\hline Age of the patients & $56(7.6)$ & $55(8.9)$ & $56(8.3)$ & 0.660 \\
\hline Age upon the illness & $55(7.6)$ & $54(8.8)$ & $54(8.3)$ & 0.291 \\
\hline
\end{tabular}

*Student's t- test

Table 2. The main features of the patients by groups

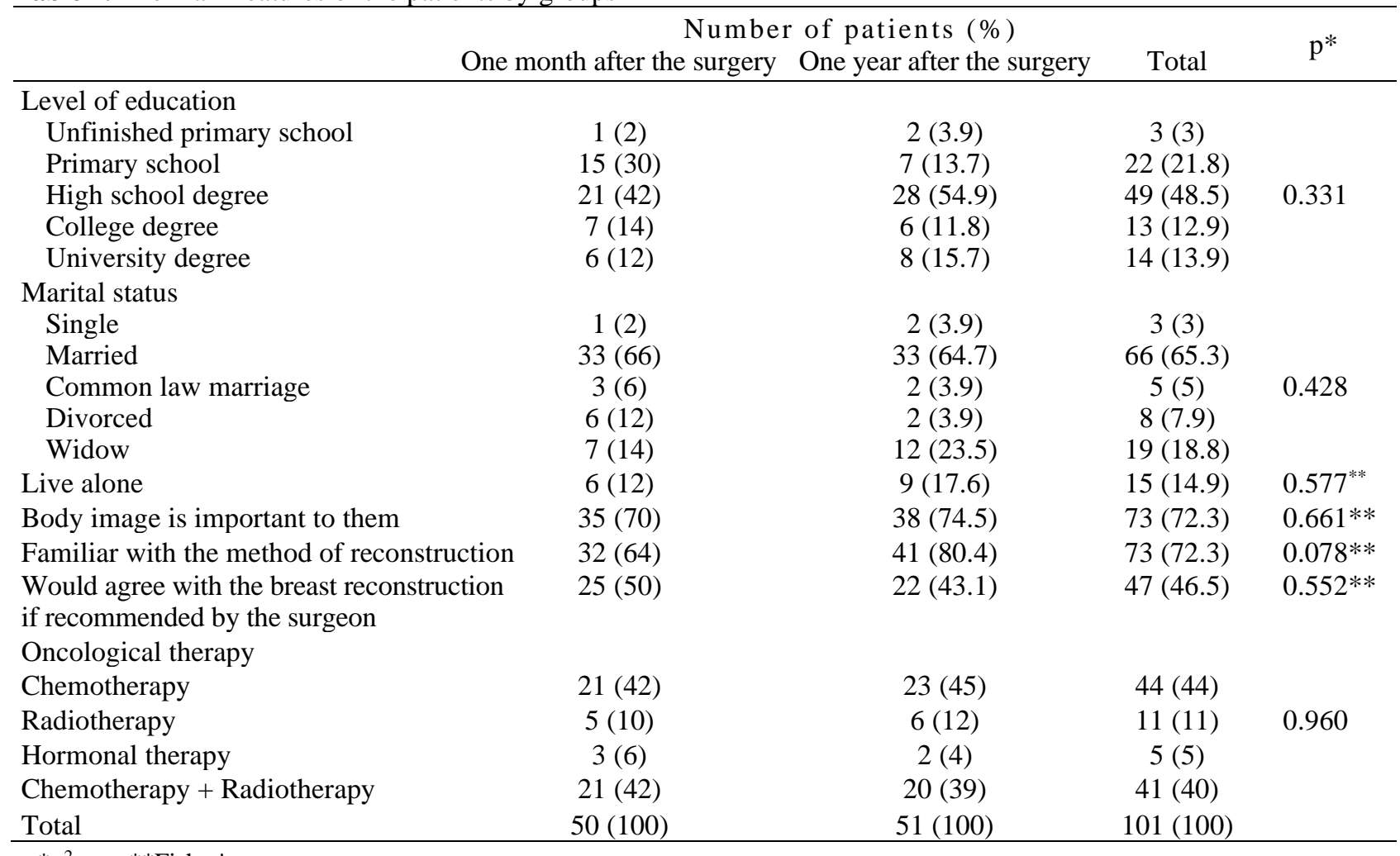

$* \chi^{2}$ test; $* *$ Fisher's exact test 
Table 3. Self-assessment of difficulties and feelings a month and a year after surgery

\begin{tabular}{lccc}
\hline & \multicolumn{2}{c}{ Median (interquartile range) } & \multirow{2}{*}{ A month after surgery } \\
& A year after surgery & $\mathrm{p}^{*}$ \\
\hline Did they have concentration problems & $1.5(1-2)$ & $1(1-2)$ & 0.222 \\
Did they feel tense & $3(2-3)$ & $2(1-3)$ & 0.011 \\
Did they feel worried & $3(2-3)$ & $2(2-3)$ & 0.065 \\
Did they feel irritable & $3(2-3)$ & $2(2-3)$ & 0.013 \\
Did they feel depressed & $3(1-3)$ & $2(1-3)$ & 0.059 \\
Did they have memory problems & $2(1-2)$ & $1(1-2)$ & 0.008 \\
Did they feel less physically attractive & $2(1-3.3)$ & $2(1-2)$ & 0.155 \\
Did they feel less feminine due to illness & $2(1-4)$ & $2(1-3)$ & 0.078 \\
Did they feel uncomfortable looking in the mirror & $2.5(1-4)$ & $2(1-3)$ & 0.113 \\
Were they dissatisfied with their body & $3(1-4)$ & $2(1-3)$ & 0.067 \\
Did they experience discomfort due to hair loss & $3(2-4)$ & $2(1-3)$ & 0.057 \\
\hline
\end{tabular}

*Mann-Whitney U test; ** higher score correlates to higher level of symptoms

Table 4. Connection between discomfort with hair loss and emotional and sexual functioning

\begin{tabular}{lcc}
\hline & \multicolumn{2}{c}{$\begin{array}{c}\text { Spearman's correlation coefficient }(p \text {-value }) \\
\text { parameter with discomfort with hair loss }\end{array}$} \\
& A month after surgery & A year after surgery \\
\hline Did they have concentration problems & $0.203(0.319)$ & $0.402(0.064)$ \\
Did they feel tense & $0.513(0.007)$ & $0.267(0.229)$ \\
Did they feel worried & $0.645(<0.001)$ & $0.191(0.393)$ \\
Did they feel irritable & $0.556(0.003)$ & $0.306(0.166)$ \\
Did they feel depressed & $0.587(0.002)$ & $0.267(0.231)$ \\
Did they have memory problems & $0.502(0.009)$ & $-0.190(0.397)$ \\
Did they feel less physically attractive & $0.647(<0.001)$ & $0.129(0.567)$ \\
Did they feel less feminine due to illness & $0.638(<0.001)$ & $0.174(0.438)$ \\
Did they feel uncomfortable looking in the mirror & $0.581(0.002)$ & $0.166(0.461)$ \\
Were they dissatisfied with their body & $0.495(0.010)$ & $0.398(0.066)$ \\
\hline
\end{tabular}

\section{RESULTS}

Among 101 patients enrolled in the study, 50 $(49.5 \%)$ had undergone mastectomy 1 month earlier and $51(50.5 \%)$ had undergone mastectomy one year earlier. All the participants were white females. The mean age of participants was 56 years and 54 years, one month and one year after mastectomy, respectively. 49 (48.5\%) participants finished secondary education. 66 (65.3\%) participants were married. Sociodemographic characteristics are listed in Tables 1 and 2.

Compared to results one month after mastectomy, in women one year after mastectomy there was significantly less tension (Mann-Whitney U test, $\mathrm{p}=0.011$ ) and emotional irritability (Mann-Whitney $U$ test, $\mathrm{p}=0.013$ ), also the memory problems declined (MannWhitney U test, $\mathrm{p}=0.008$ ).

The difference was not statistically significant in other studied parameters (Table 3).

Discomfort with hair loss significantly affected all parameters (mostly the feeling of being less physically attractive $(\rho=0.647)$. The feelings of being worried ( $\rho=0.645$ ) and being less feminine due to illness $(\rho=0.638)$ increased a year after mastectomy, whereas the problem with concentration declined. There was no connection between discomfort with hair loss with the observed parameters a year after surgery (Table 4).

\section{DISCUSSION}

This study focused on emotional functioning of postmastectomy women and their problems related to selfperception. The study enrolled patients one month after mastectomy when they have recovered from the surgery and are starting to deal with the effects of illness and treatment and the women one year after mastectomy when they have finished adjuvant therapies and are already accustomed to disease-specific changes. Previous study had shown that both functional and symptom scales were more affected one month after mastectomy then one year after mastectomy (Pačarić et al. 2018). Functional scales' results (emotional, cognitive and body image) were lower in the group who had mastectomy a month ago since after the surgery the participants often felt tense and emotionally irritable. A year post mastectomy, they rarely experienced memory problems. After surgery, the participants expressed they had felt afraid, unwell, strange and different when they had seen their place in 
the operating room. They also realized the connection between various consequences of mastectomy. Some of them understood that their health was more important than losing a breast, while in others losing a breast led to sadness (Nakatani et al. 2013, Koçan \& Gürsoy 2016).

Negative consequences of breast cancer and its treatment may cause dramatic changes in patients' mental health and their relationships with the members of their families (Goerling et al. 2020). Studies conducted on quality of life in breast cancer patients showed that there is a need to provide better emotional support to patients' families (Svetina \& Nastran 2012) and the whole community in order to help breast cancer patients improve their emotional and social functioning (Gavric \& Vukovic-Kostic 2016). Psychosocial disorders include broad range of affective and cognitive problems which surpass the psychiatric diagnosis of the main depressive illness or anxiety disorder. They vary from specific concerns about the cancer, such as reoccurrence, to general symptoms, such as worries, sleeping disorder, tiredness and concern about seeing the doctor. Also, relevant literature on psychosocial pain includes several global and broad concepts within the framework of quality of life, such as emotional well-being (DeMiglio et al. 2020).

The loss of a breast causes trauma which affects patient's quality of life not only because it is a part of the female reproductive system, but also for being a symbol of femininity (Baize et al. 2008). This study results showed that the majority of patients were unsatisfied with their body, felt less attractive, and experienced discomfort with hair loss due to mastectomy and cancer treatment side effects. Some previous studies have shown that most of women, during the first few months after diagnosis, had problems with their body image related to mastectomy, possible breast reconstruction, hair loss due to chemotherapy, and weight loss worries. Those women had poor mental health, lower self-esteem, and difficulties with understanding their feelings by their partners. Some symptoms, such as hair loss, are believed to be only temporary without long term consequences. Other symptoms, such as vaginal dryness caused by early and sudden onset of menopause, can have longer negative impact on patients' lives (Fobair et al. 2006, Janz et al. 2005). Our study showed that discomfort with hair loss significantly affected all parameters a month after mastectomy, except the problem with concentration. These results are contrary to the results of the study conducted in Poland which showed that post mastectomy women subjected all their activities and thoughts to the new situation which demanded care because of lower stamina and tiredness from coping with the disease (Mącik et al. 2012). Being concentrated on the disease, as well as feeling nauseous and worried, can lead to patients not having the need to understand themselves or being able to do it. Patients would not be interested in recognizing the source of negative emotions, or in overcoming them because they were subconsciously afraid of psychic pain which may follow that process (Mącik et al. 2012). Alopecia is a common chemotherapy side effect. Hair loss causes anxiety and may have influence on body image (Lemieux 2008). Many patients stated that they had decided to wear a wig in order to disguise their baldness which reminded them of their disease every time they looked in the mirror (van den Hurk 2013). One study on group of women who lost their hair due to chemotherapy, found four reactions common to most of patients in the group: they were not prepared; they were in shock; they felt embarrassed; they felt as if they had lost their identity. They also had lower self-esteem, lower quality of life and lower body image (Erol et al. 2012). Our results showed that in a year post mastectomy there was no connection between discomfort with hair loss and emotional functioning.

Education on suitable interventions used for coping with the disease can lower the negative impact on body image. The most effective interventions were a cognitive confronting strategy, social support and adjustment. Furthermore, the quality of life was lower due to development of psychological problems, such as anxiety and depression. Especially in the first-year post diagnosis, breast cancer was connected to anxiety and confusion in relation to body image, since the breast is one of the most important organs which influence the body image of a woman (Paterson 2016, Alicikus 2009, Moreira \& Canavarro 2010). A study which researched body image and quality of life of young and middle-aged post mastectomy women showed their dissatisfaction with body image. Those results led to conclusion that post mastectomy women were aware of their body image, felt less physically attractive, were dissatisfied with the way they dress, and lost their femininity all due to breast cancer treatment (Tariq \& Hasan 2015). Maurer and associates (Maurer et al. 2021) indicated that younger women who were diagnosed with breast cancer face more difficulties while adjusting than older women. Younger women also have lower overall quality of life regarding worries about body image, relationship with their partner, sexual functioning and less adaptive styles of confronting the disease. Gradual decrease in psychological stress can result in improvement of quality of life subscales, such as body image and emotional functions (Speck 2010).

Higher levels of anxiety at the beginning can be connected to lack of information about breast cancer, as well as to poor understanding of the course of the disease and treatment side effects (Marijanović et al. 2017). As the patients gained knowledge, their anxiety about the unknown decreased. Literature also showed that following the instructions about the treatment decreased the anxiety (Tuncer \& Yucel 2014). Lower body image usually improved with time. The more time from the surgery had passed, the more acceptable became the body (Zanapalioglun 2009). Those results were in accordance with our results. There was no connection between anxiety and observed parameters. 


\section{CONCLUSION}

Breast cancer diagnosis and treatment has an impact on patients' emotional functioning and body-image selfperception. These problems are more pronounced during early post mastectomy period when women often feel tense and emotionally irritable. Discomfort with hair loss is one of major problems and affects almost all studied parameters significantly. One year following mastectomy the problems decline. Therefore, it is important to be aware of these problems, to advise the patients before and after surgery and to provide medical, social and psychological support during and after breast cancer treatment.

\section{Acknowledgements: None.}

\section{Conflict of interest: None to declare.}

\section{Contribution of individual authors:}

Stana Pačarić: design of the study, literature searches and analyses, interpretation of data, drafting of the article;

Želimir Orkić, Ivan Erić \& Goran Kondža: design of study, interpretation of data;

Tajana Turk \& Ivana Barać: statistical analyses, literature searches, critical revision of the article;

Nikolina Farčić: data collecting, literature searches, critical revision of the article;

Marta Biljan: data collecting, literature searches;

Zvjezdana Gvozdanović \& Ana Nemčić: data collecting, interpretation of data;

Andrea Milostić-Srb: data collecting.

\section{References}

1. Alicikus ZA, Gorken IB, Sen RC, Kentli S, Kinay M, Alanyali $H$, et al.: Psychosexual and body image aspects of quality of life in Turkish breast cancer patients: a comparison of breast conserving treatment and mastectomy. Tumori 2009; 95:212-8

2. Baize N, Mounier N, Bongain A, Spano JP. Femininity and breast cancer, original approach of announcement in oncology. Bull Cancer 2008; 95:849-57

3. Cardoso F, Kyriakides S, Ohno S, Penault-Llorca F, Poortmans P, Rubio IT, et al.: Primary breast cancer: ESMO Clinical practice guidelines for diagnosis, treatment and follow up. Ann Oncol 2019; 30:1194-220

4. Choi EK, Kim IR, Chang O, Kang D, Nam SJ, Lee JE, Lee SK, Im YH, Park YH, Yang JH, Cho J: Impact of chemotherapy-induced alopecia distress on body image, psychosocial well-being, and depression in breast cancer patients. Psychooncology 2014; 23:1103-10

5. Coe K, Staten L, Rosales C, Swanson M: The enigma of the stigma of hair loss: why is cancer-treatment related alopecia so traumatic for women? Open Cancer J 2013; 6:1-8

6. de la Torre-Luque A, Gambara H, López E, Cruzado JA: Psychological treatments to improve quality of life in cancer contexts: A meta-analysis. Int J Clin Health Psychol 2016; 16:211-19

7. de Morais FD, Freitas-Junior R, Rahal RM, Gonzaga CM: Sociodemographic and clinical factors affecting body image, sexual function and sexual satisfaction in women with breast cancer. J Clin Nurs 2016; 25:1557-65

8. Dujmović A, Marčinko D, Bulić K, Kisić K, Duduković M, Mijatović D: Quality of life and depression among female patients undergoing surgical treatment for breast cancer: $a$ prospective study. Psychiatr Danub 2017; 29:345-50

9. DeMiglio L, Murdoch V, Ivison J, Fageria S, Voutsadakis IA: Factors influencing psychological wellbeing of early breast cancer patients. Rep Pract Oncol Radiother 2020; 25:913-18

10. Erol O, Can G, Aydiner A: Effects of alopecia on body image and quality of life of Turkish cancer women with or without headscarf. Support Care Cancer 2012; 20:2349-56

11. Fallowfield L \& Jenkins V: Psychosocial/survivorship issues in breast cancer: are we doing better? J Natl Cancer Inst 2015; 107:335

12. Fayers PM, Aaronson NK, Bjordal K, Groenvold M, Curran D, Bottomley A, on behalf of the EORTC Quality of Life Group: The EORTC QLQ-C3O Scoring Manual. European Organisation for Reasearch and Treatmenr of Cancer, Brussels, 2001

13. Fingeret MC, Teo I, Epner DE: Managing body image difficulties of adult cancer patients: lessons from available research. Cancer 2014; 120:633-41

14. Fobair P, Stewart SL, Chang S, D'Onofrio C, Banks PJ, Bloom JR: Body image and sexual problems in young women with breast cancer. Psychooncology 2006; 15:579-94

15. Gavric Z \& Vukovic-Kostic Z: Assessment of quality of life of women with breast cancer. Glob J Health Sci 2016; 8:1-9

16. Goerling U, Bergelt C, Müller V, Mehnert-Theuerkauf A: Psychosocial distress in women with breast cancer and their partners and its impact on supportive care needs in partners. Front Psychol 2020; 11:564079

17. Gregurek R, Braš M, Đorđević M, Strahinja Ratković A \& Brajković L: Psychological problems of patients with cancer. Psychiatr Danub 2010; 2:227-30

18. Harris JR, Lippman ME, Veronesi $U$, Willett $W$ : Diseases of the Breast, 2nd ed. Lippincott Williams \& Wilkins, Philadelphia, 2000

19. Härtl K, Schennach R, Müller M, Engel J, Reinecker H, Sommer $H$, et al: Quality of life, anxiety, and oncological factors: a follow-up study of breast cancer patients. Psychosomatics 2010; 51:112-23

20. Hrvatski zavod za javno zdravstvo, Registar za rak Republike Hrvatske. Incidencija raka u Hrvatskoj 2015, Bilten 40, Zagreb, 2018. Dostupno na: https://www.hzjz.hr/sluzbaepidemiologija-prevencija-nezaraznih-bolesti/odjelzamaligne-bolesti/ Datum pristupanja 10.04.2018

21. Husić S \& Brkljačić Žagrović M: Quality of life disorder after mastectomy for breast cancer and the body image changes. Medicina Fluminensis 2010; 46:80-5

22. Janz NK, Mujahid M, Lantz PM, Fagerlin A, Salem B, Morrow M, et al: Population-based study of the relationship of treatment and sociodemographics on quality of life for early stage breast cancer. Qual Life Res 2005; 14:1467-79

23. Kanti V, Nuwayhid R, Lindner J, Hillmann K, Stroux A, Bangemann N, et al: Analysis of quantitative changes in hair growth during treatment with chemotherapy or tamoxifen in patients with breast cancer: a cohort study. Br J Dermatol 2014; 170:643-50

24. Keskin $G$ \& Gumus AB: Turkish hysterectomy and mastectomy patients depression, body image, sexual problems and spouse relationships. Asian Pac Cancer Prev 2011; 12:425-32 
25. Koçan $S$ \& Gürsoy A: Body image of women with breast cancer after mastectomy: a qualitative research. J Breast Health 2016; 12:145-50

26. Kreiter E, Richardson A, Potter J, Yasui Y: Breast cancer: trends in international incidence in men and women. $\mathrm{Br} \mathrm{J}$ Cancer 2014; 110:1891-7

27. Lara LA, de Andrade JM, Consolo FD, Romão AP: Women's poorer satisfaction with their sex lives following gynecologic cancer treatment. Clin J Oncol Nurs 2012; 16:273-7

28. Lemieux J, Maunsell E, Provencher L: Chemotherapyinduced alopecia and effects on quality of life among women with breast cancer: a literature review. Psychooncology 2008; 17:317-28

29. Macik D, Ziótkowska P, Kowalska M: Self-perception of women after mastectomy as an ego defence mechanism. Comparison with a group of healthy women. Contemp Oncol 2012; 16:184-90

30. Marijanović I, Pavleković G, Buhovac T \& Martinac M: The relationship between health locus of control, depression, and sociodemographic factors and amount of time breast cancer patients wait before seeking diagnosis and treatment. Psychiatr Danub 2017; 29:330-44

31. Maurer T, Thöne K, Obi N, Jung AY, Behrens S, Becher $H$, et al.: Health-related quality of life in a cohort of breast cancer survivors over more than 10 years postdiagnosis and in comparison, to a control cohort. Cancers 2021; 13:1854

32. Mirmirani P: Managing hair loss in midlife women. Maturitas 2013; 74:119-22

33. Moreira $H$ \& Canavarro MC: A longitudinal study about the body image and psychosocial adjustment of breast cancer patients during the course of the disease. Eur $J$ Oncol Nurs 2010; 14:263-70

34. Murgić J, Soldić Ž, Vrljić D, Samija I, Kirac I, Bolanca A, Kusić Z: Quality of life of Croatian breast cancer patients receiving adjuvant treatment - comparison to long-term breast cancer survivors. Coll Antropol 2012; 6:1335-41

35. Nakatani $Y$, Iwamitsu $Y$, Kuranami M, Okazaki SH: Predictors of psychological distress in breast cancer patients after surgery. Kitasato Med J 2013; 43:49-56

36. Pačarić S, Kristek J, Mirat J, Kondža G, Turk T, Farčić N, Orkić Ž, Nemčić A: The quality of life of Croatian women after mastectomy: a cross-sectional single-center study. BMC Public Health 2018; 18:999

37. Paterson C, Lengacher CA, Donovan KA, Kip KE, Tofthagen CS: Body image in younger breast cancer survivors: a systematic review. Cancer Nurs 2016; 39:E39-E58

38. Przezdziecki A, Sherman K, Baillie A, Taylor A, Foley E, Stalgis-Bilinski K: My changed body: breast cancer, body image, distress and self-compassion. Psychooncology $2012 ; 22: 1872-9$

39. Recio-Saucedo A, Gerty S, Foster C, Eccles D, Cutress RI: Information requirements of young women with breast cancer treated with mastectomy or breast conserving surgery: a systematic review. Breast 2016; 25:1-13
40. Rossi S, Schinzari G, Basso M, Strippoli A, Dadduzio V, D'Argento E, Cassano A, Barone C: Maintenance hormonal and chemotherapy treatment in metastatic breast cancer: a systematic review. Future Oncol 2016; 12:1299-307

41. Shilling V, Jenkins V, Morris R, Deutsch G, Bloomfield D: The effects of adjuvant chemotherapy on cognition in women with breast cancer - preliminary results of an observational longitudinal study. Breast 2005; 14:142-50

42. Słowik AJ, Jabłoński MJ, Michałowska-Kaczmarczyk AM, Jach R: Evaluation of quality of life in women with breast cancer, with particular emphasis on sexual satisfaction, future perspectives and body image, depending on the method of surgery. Psychiatr Pol 2017; 51:871-88

43. Speck RM, Gross CR, Hormes JM, Ahmed RL, Lytle LA, Hwang WT: Changes in the body image and relationship scale following a one-year strength training trial for breast cancer survivors with or at risk for lymphedema. Breast Cancer Res Treat 2010; 121:421-30

44. Speers $C$ \& Pierce LJ: Postoperative radiotherapy after breast-conserving surgery for early-stage breast cancer: $a$ review. JAMA Oncol 2016; 2:1075-82

45. Stanton AL: What happens now? Psychosocial care for cancer survivors after medical treatment completion. $J$ Clin Oncol 2012; 30:1215-20

46. Svetina $M \&$ Nastran $K$ : Family relationships and posttraumatic growth in breast cancer patients. Psychiatr Danub 2012; 24:298-306

47. Šeparović R, Silovski T, Tecić Vuger A, Bajić Ž, Silovski $H$ \& Jurić A: Association of breast cancer symptoms with patients' quality of life and depression; A Croatian crosssectional study. Psychiatr Danub 2019; 31(Suppl 1):92-8

48. Tariq A \& Hasan SS: Body image and quality of life of young and middle aged married Pakistani mastectomy breast cancer patients. FWU J Soc Sci 2015; 9:32-9

49. Teo I, Reece GP, Christie IC, Guindani M, Markey MK, Heinberg LJ, Crosby MA, Fingeret MC: Body image and quality of life of breast cancer patients: influence of timing and stage of breast reconstruction. Psychooncology 2016; 25:1106-1

50. Tuncer G \& Yucel SC: Comfort and anxiety levels of women with early stage breast cancer who receive radiotherapy. Asian Pac J Cancer Prev 2014; 15:2109-14

51. van den Hurk CJG: Safety and effectiveness of scalp cooling in cancer patients undergoing cytotoxic treatment. Thesis. Leiden University Medical Center, Leiden, 2013

52. You $J \& L u Q$ : Social constraints and quality of life among Chinese-speaking breast cancer survivors: a mediation model. Qual Life Res 2014; 23:2577-84

53. Zavos A, Valachis A: Risk of chemotherapy-induced amenorrhea in patients with breast cancer: a systematic review and meta-analysis. Acta Oncol 2016; 55:664-70

54. Zanapalioglun Y, Atahan K, Gur S, Çökmez A, Tarcan E: Effect of breast conserving surgery in qality of life in brest cancer patients. J Breast Health 2009; 3:152-6

Correspondence:

Nikolina Farčić, MSc RN

Surgical Clinic, University Hospital Centre Osijek

Josipa Huttlera 4, 31000 Osijek, Croatia

E-mail:nikolina.farcic@mefos.hr 